\title{
Epidemiological Study of Pediatric Surgery at Regional Hospital of Sorocaba between 2008 and 2012 by a Single Surgeon
}

\author{
Raíssa Teixeira Rosalino¹, Natália Iwakura Martelli¹, Neil F. Novo², Willy Marcus França ${ }^{3 *}$ \\ ${ }^{1}$ Medical Science and Health Faculty, Pontifical Catholic University of São Paulo (PUC-SP), São Paulo, Brazil \\ ${ }^{2}$ Department of Medicine, Service of Statistical Studies of Pontifical Catholic University of São Paulo (PUC-SP), São Paulo, Brazil \\ ${ }^{3}$ Medical Science and Health Faculty, Pontifical Catholic University of São Paulo (PUC-SP), São Paulo, Brazil \\ Email: *willy@drwilly.com.br
}

How to cite this paper: Rosalino, R.T., Martelli, N.I., Novo, N.F. and França, W.M. (2017) Epidemiological Study of Pediatric Surgery at Regional Hospital of Sorocaba between 2008 and 2012 by a Single Surgeon. Surgical Science, 8, 375-383. https://doi.org/10.4236/ss.2017.88041

Received: April 16, 2017

Accepted: August 20, 2017

Published: August 23, 2017

Copyright (c) 2017 by authors and Scientific Research Publishing Inc. This work is licensed under the Creative Commons Attribution International License (CC BY 4.0). http://creativecommons.org/licenses/by/4.0/

\section{Open Access}

\begin{abstract}
Introduction: volume increase of Pediatric Surgery (PedSur) due to factors not yet fully clarified contrast with the scarcity of pediatric surgeons in Brazil and globally. Geographic distribution, surgical care costs, and graduation period might contribute to this dearth. In Brazil, vacancy occupation rate in PedSur is below 43\% (162 vacancies/year). Aim: analyze the volume of procedures performed on 0 - 12 year-old patients in PedSur by a single Specialist at Hospital Regional (HR); compare with the literature and propose the outset of a PedSur Medical Residence program. Material \& Method: 1912 attendances were fulfilled on 986 children who were submitted to surgical procedures between 2008 and 2012 at HR by a single specialist. Results: Surgical procedures were performed on 1137 children, an average of 227/year or 197 children per year. Surgery was carried out in 667 (68\%) boys and 319 (32\%) girls. Hernias, appendectomies and circumcisions were the most frequent external surgeries. 437 (44\%) patients were discharged on the same day and, 549 (56\%) were hospitalized. In the Pediatric ICU and in the Neonatal ICU 181 procedures were performed (18\%). Conclusion: It was possible to make evident the distribution of surgeries on children, the degree of complexity and a sufficient number of subjects for training in this Specialty. The obtained data allow the development of a study with regards to the inception of a Medical Residence in PedSur at HR for training and retaining the professional in the region.
\end{abstract}

\section{Keywords}

Patient Care, Pediatric Surgery, Epidemiology, Resident, Education 


\section{Introduction}

Despite the increase of volume in Pediatric Surgery (PedSur), there is a decrease in the working capacity of pediatric surgeons in USA and worldwide which has not been properly clarified [1] [2]. Geographic distribution, surgical care costs, social statistics and this specialist graduation period might explain this still limited distribution of labor force in PedSur [2]. A significant group of children have been operated by other specialties, such as urology, whereas pediatric surgeons are usually engaged in the correction of hernias (primary and recurrent), corrections using laparoscope in younger children and girls. On the other hand, pediatric urologists operate most frequently hydrocelectomies (62\%), orchiopexies (83\%) [3].

In a research done through the Internet with members of the American Pediatric Surgery Association (APSA), a minority of PedSur specialists who answered the questionary asserted that unspecialized PedSur surgeons have treated selected children cases in their communities. In their replies, they mentioned inguinal, umbilical hernias; abscesses and trauma. Nearly $20 \%$ of the respondents expressed interest to count on a PedSur partner who would substitute them in their surgical procedures [4].

Despite the scarcity of pediatric surgeons, training programs in PedSur have had a swift growth in North America. Moreover, the quality of patient care, surgical education, practical activities and training are thoroughly monitored [5]. A research in Canada and USA was conducted and analyzed by categories, such as neonatal; oncologic; thoracic; cardiac; urologic; reconstructive; head and neck; vascular, plastic surgeries procedures in burned patients. Routine surgeries showed a slight difference between training programs, as well as experience among surgeons. There are services in which PedSur iconic surgeries, such as esophagus atresia, bile duct atresia, and inter-sex atresia are scarce or not performed in some training programs [4]. In spite of this upturn in PedSur programs, it doesn't seem that they have significantly affected the exposure to and surgical experience in highly specific specialties. Moreover, PedSur programs have concurred that there is a growing variability among these programs [6].

It was not only the amount, the type of surgeries performed, and the surgeons' experience that was studied in the different services offered at PedSur. Teaching quality in Medical Schools was also analyzed. In spite of the inclusion of the concept of quality improvement of the curriculum of several Medical Schools in USA and United Kingdom, there are significant differences in the offer of these topics in the undergraduate and in the period of medicine students' qualification that has shown variable degrees of exposure to the concept of quality improvement [7]. In 2013, 90 thousand deaths were attributed to medical malpractice in the USA. Since then, the introduction of a curricular program for the patients' safety and quality improvement in medical schools has become the focus of study worldwide. Despite this consensus, few medical schools have implemented directives aimed at this objective. Moreover, there are few evidences regarding an 
improved teaching method for this subject [8].

In Brazil, the concern is not only PedSur services, but the lack of interest and consequently these specialty services don't attract students, as described by Jesus et al., 2009 [9]. The latter can be verified by comparing the numbers of openings offered for enrollment in PedSur in Brazil (162) and the number of openings filled (70, or merely $43 \%$ ). These authors have also assessed PedSur qualification degree using the best results, especially in trauma, appendicitis, urological cases and specialties related to other cases when children are operated. "The ideal solution would be the increment of professionals' attending availability" that suggests the possibility of graduating new specialized professionals in PedSur [9].

The health attending level of Hospital Regional (HR) at the Conjunto Hospitalar de Sorocaba (CHS) is at the tertiary health attention level (high complexity), providing care to a population of more than 3 million inhabitants of $48 \mathrm{mu}$ nicipalities of the Southwest of the State of São Paulo. In this capacity, the volume of patients allows adequate comprehensively academic development in PedSur that permits the inception of a comprehensive Academic Program in PedSur Medical Residence at HR/CHS (http://www.chshospital.com.br/home/index.htm) in 08/10/2016 [10]. Overall, there are six professionals specialized in PedSur who attend at CHS, but the data shown in this study are only the result of the work of an individual surgeon. His data indicate an increase of $8 \%$ in attending volume between 2009 (420) and 2012 (454), and 5\% increase in the number of surgeries performed in the same period in 2009 (222) and 2012 (233), an evolution with similar tendency to the increase presented in the literature [2] [5].

The objective of the actual retrospective descriptive study was to analyze the magnitude of 1137 procedures performed on 986 children with ages from 0 to 12 years by an individual Pediatric Surgeon at the PedSur Service of HR/CHS between 2008 and 2012 comparing data obtained with other published studies [2]. Moreover, this study aims at demonstrating the feasibility of a Medical Residency start-up program in Pediatric Surgery at HR/CHS. These new specialists shall be part of the work force in PedSur in the city and the region [4].

\section{Material \& Method}

In this retrospective descriptive study of 1912 documented attendances in the Book of Ambulatory Attendance of an individual Pediatric Surgeon between 2008 and 2012 at HR/CHS in PedSur specialty were analyzed. In this Service, there are 5 other professionals of the same specialty, whose surgeries were not assessed in this analysis. All the information detailed in the book is described in the present study.

The information obtained from the data of 1137 surgical procedures performed in 986 children is shown per year, per hospitalization regimen and type of surgery.

\section{Results}

In the period of February 2008 to December 2012, a total of 1912 consultations 
of an individual pediatric surgeon to whom 986 children were referred by the Pediatric Surgery ambulatory due to surgical diagnoses. As a result, an average of 383 attendances/year and 197 children were operated per year (Table 1).

In surgeries totalizing 1137 procedures performed in 986 children, 437 (44\%) were medically discharged on the same day after an observation period of $4-5$ hours. Additional 549 children (56\%) were operated in a prolonged hospitalization regimen (Table 2).

In 2008, 193 children were submitted to 224 surgical procedures (20\%) of which 129 were boys (67\%) and 64 girls (33\%). In 2009, 191 children were submitted to 222 surgical procedures (20\%) of which 130 were boys (68\%) and 61 girls (32\%). In 2010, 195 children were submitted to 227 surgical procedures (20\%) of which 140 were boys (72\%) and 55 girls (28\%). In 2011, 204 children were submitted to 231 surgical procedures (20\%) of which 137 were boys (67\%) and 67 girls (33\%). In 2012, 203 children were submitted to 233 surgical procedures (20\%) of which 131 were boys (65\%) and 72 girls (35\%). Total numbers of boys and girls submitted to surgery were 667 (68\%) and 319 (32\%), respectively (Table 2).

Regarding the 1137 surgical procedures performed on 986 children, 437 (44\%) were discharged on the same day after a period of observation of 4 - 5 hours on the average. Other 549 children (56\%) were operated with a prolonged hospitalization regimen (Table 2).

Table 3 shows the distribution of the children who were submitted to surgery in the period between 2008 and 2012 by type of surgery and gender. In the group of children who were operated 667 were boys (68\%) and 319 girls (32\%). More

Table 1. Distribution of appointments, patients and surgeries in the years 2008 up to 2012. The number of appointments is higher than the surgeries, given that some children were attended at the ambulatory more than once.

\begin{tabular}{cccc}
\hline Year & $\mathbf{N}^{\bullet}$ Appointments & $\mathbf{N}^{\bullet}$ Patients & $\mathbf{N}^{\bullet}$ Surgeries \\
\hline 2008 & 471 & 193 & 224 \\
2009 & 420 & 191 & 222 \\
2010 & 230 & 195 & 227 \\
2011 & 337 & 204 & 231 \\
2012 & 454 & 203 & 233 \\
& $1912^{*}$ & $\mathbf{9 8 6}$ & $\mathbf{1 1 3 7 ^ { * * }}$ \\
\hline
\end{tabular}

${ }^{*}$ Average of 383 attendances per year. ${ }^{* * 227}$ surgeries per year per individual surgeon.

Table 2. Distribution of surgical procedures in day hospital (44\%) and in prolonged hospitalization regimen $(56 \%)$.

\begin{tabular}{ccc}
\hline Hospital Admission & N & $\%$ \\
\hline Outpatients & 437 & $44 \%$ \\
Inpatients & 549 & $56 \%$ \\
Total & $\mathbf{9 8 6}$ & \\
\hline
\end{tabular}


Table 3. Distribution of children submitted to surgical procedures by surgery type and sex from 2008 up to 2012, in addition to the sectors of Ped ICU (PICU) and Neonatal ICU (NICU).

\begin{tabular}{|c|c|c|c|c|c|c|c|c|c|c|c|c|c|}
\hline Year & \multicolumn{2}{|c|}{2008} & \multicolumn{2}{|c|}{2009} & \multicolumn{2}{|c|}{2010} & \multicolumn{2}{|c|}{2011} & \multicolumn{2}{|c|}{2012} & \multirow{2}{*}{ Total } & \multirow{2}{*}{$\%$} & \\
\hline Diagnostic & Boys & Girls & Boys & Girls & Boys & Girls & Boys & Girls & Boys & Girls & & & \\
\hline Appendectomy & 23 & 17 & 18 & 12 & 18 & 11 & 22 & 14 & 23 & 21 & 179 & 18 & \\
\hline Anorectal Malform. & 1 & 2 & 2 & 3 & 2 & 1 & 1 & 2 & 2 & 3 & 19 & 5 & \\
\hline BIH (Circumcis/boys) & 7 & 2 & 8 & 3 & 8 & 4 & 8 & 1 & 7 & 3 & 51 & & \\
\hline Bilateral Orchiopexy & 1 & 0 & 1 & 0 & 2 & 0 & 1 & 0 & 2 & 0 & 7 & & \\
\hline Bilateral Ing. Hernia & 9 & 4 & 8 & 4 & 5 & 3 & 7 & 4 & 6 & 4 & 54 & & \\
\hline Colostomy & 4 & 1 & 5 & 1 & 3 & 1 & 3 & 1 & 1 & 2 & 22 & 2 & \\
\hline Circumcision & 16 & 0 & 27 & 0 & 27 & 0 & 32 & 0 & 22 & 0 & 124 & 13 & \\
\hline Congenital Diaphragmatic Hernia & 1 & 1 & 0 & 2 & 1 & 1 & 2 & 1 & 1 & 0 & 10 & 1.0 & \\
\hline Duodenal Atresia & 1 & 0 & 1 & 1 & 0 & 1 & 0 & 2 & 1 & 1 & 8 & 0.8 & \\
\hline Epigastric Hernia & 2 & 0 & 3 & 1 & 3 & 0 & 0 & 0 & 2 & 1 & 12 & & \\
\hline Esophageal Atresia & 1 & 1 & 0 & 1 & 2 & 0 & 1 & 1 & 1 & 1 & 9 & 0.9 & \\
\hline G. E. Reflux (Fundoplication) & 3 & 1 & 2 & 2 & 1 & 2 & 2 & 3 & 3 & 2 & 21 & 2.1 & \\
\hline Gastrostomy & 7 & 4 & 3 & 2 & 1 & 0 & 2 & 1 & 1 & 2 & 23 & 2.1 & \\
\hline Gastroschisis & 1 & 2 & 2 & 1 & 3 & 1 & 2 & 2 & 1 & 1 & 16 & 1.6 & \\
\hline Hypospadia & 6 & 0 & 7 & 0 & 4 & 0 & 6 & 0 & 8 & 0 & 31 & 3.1 & \\
\hline ICU/NICU (Others) & 18 & 15 & 11 & 16 & 22 & 21 & 16 & 21 & 16 & 25 & 181 & 18 & \\
\hline Left Inguinal Hernia & 6 & 2 & 2 & 1 & 4 & 1 & 4 & 2 & 3 & 1 & 26 & & \\
\hline Left Orchiopexy & 5 & 0 & 7 & 0 & 6 & 0 & 9 & 0 & 8 & 0 & 35 & & \\
\hline LIH (Circuncis/Boys) & 3 & 1 & 2 & 0 & 4 & 0 & 3 & 0 & 2 & 0 & 15 & & \\
\hline Omphalocele & 0 & 0 & 1 & 2 & 1 & 0 & 1 & 2 & 1 & 0 & 8 & 0.8 & \\
\hline Pylorus Stenosis & 1 & 1 & 1 & 0 & 2 & 0 & 1 & 1 & 1 & 0 & 8 & 0.8 & \\
\hline Right Inguinal Hernia & 3 & 1 & 5 & 1 & 4 & 2 & 3 & 1 & 2 & 1 & 23 & & \\
\hline Right Orchiopexy & 3 & 0 & 5 & 0 & 9 & 0 & 6 & 0 & 9 & 0 & 32 & & \\
\hline RIH (+Circumcis/Boys) & 3 & 1 & 5 & 0 & 5 & 1 & 3 & 0 & 6 & 0 & 24 & & \\
\hline Thyroglossal Cyst & 3 & 2 & 2 & 3 & 0 & 1 & 0 & 2 & 1 & 0 & 14 & & \\
\hline Umbilical Hernia & 1 & 6 & 2 & 5 & 3 & 4 & 2 & 6 & 1 & 4 & 34 & boys & girls \\
\hline TOTAL per Gender & 129 & 64 & 130 & 61 & 140 & 55 & 137 & 67 & 131 & 72 & & 667 & 319 \\
\hline \% Boys/Girls & 67 & 33 & 68 & 32 & 72 & 28 & 67 & 33 & 65 & 35 & 986 & $68 \%$ & $32 \%$ \\
\hline TOTAL Children & \multicolumn{2}{|c|}{193} & \multicolumn{2}{|c|}{191} & \multicolumn{2}{|c|}{195} & \multicolumn{2}{|c|}{204} & \multicolumn{2}{|c|}{203} & & & \\
\hline$>1$ Surgery/Child & 23 & 8 & 24 & 7 & 24 & 8 & 22 & 5 & 23 & 7 & 151 & 116 & 35 \\
\hline Total with Bilateral & & 224 & & 222 & & 227 & & 231 & & 233 & 1137 & $77 \%$ & $23 \%$ \\
\hline \% Year/Total & & $20 \%$ & & $20 \%$ & & $20 \%$ & & $20 \%$ & & $20 \%$ & & & \\
\hline
\end{tabular}

NOTE: In the group of 986 children, who were submitted to surgery, 667 were boys (68\%) and 319 were girls (32\%). 
than one surgical procedure was performed on 151 children (15\%); 116 boys (77\%) and 35 girls (23\%).

Employing $x^{2}$ test (chi-square test) to compare attendances described above for each year, it was observed a lower number of attendances in 2010 and 2011 in comparison with the years of 2008, 2009 and 2012. The results present a significant statistical difference $p<0.0001$.

Statistical analysis displayed in Table 1, regarding the number of patients who were attended, did not show significant statistical difference when compared to the years 2008 up to 2012 , with $p=0.9501$.

Regarding the performed surgeries shown in Table 1, statistical analysis didn't show significant statistical difference when compared to the years 2008 up to 2012 with $p=0.9843$.

From the 1137 surgical procedures performed on 986 children, 437 (44\%) were discharged on the same day after an average period of observation of 4 - 5 hours. Other 549 children (56\%) were operated on a prolonged hospitalization regimen, (Table 2). When comparing the number of operated patients who remained hospitalized with the number of patients in Day Clinic regimen, a significant statistical difference was observed, with $p=0.0004$ (the expected frequency was calculated based on the hypothesis that both were equal, that is, 493 surgeries).

Table 3 shows the distribution of children operated in the period from 2008 up to 2012 by type of surgery and sex. Within the group of children submitted to surgery 667 were boys (68\%) and 319 were girls (32\%). More than one operative procedure was performed on 151 children (15\%): 116 boys (77\%) and 35 girls (23\%).

Concerning sex, the number of boys and girls submitted to surgery was not statistically significant different concerning the percent distribution throughout the 5-year study, despite the mesmo o número de meninos ser maior ( $p=$ $0.6396)$.

In the neonatal period, 266 children $(27 \%)$ were operated and hospitalized in the Pediatric Intensive Care Unit (PICU) or in the Neonatal Intensive Care Unit (NICU). In these sectors 181 small surgical procedures, highlighted in Table 4, were performed totalizing $18 \%$ of the operated children (986). Central venous access was the most frequent technique with 111 surgical procedures (61\%) and $11 \%$ when compared to the total number of operated children (986).

Some of these children were submitted to 2 gastrostomies in 2 esophagus atresia without tracheoesophageal fistula and 13 colostomies in cases of high anorectal anomalies or in children bearing vestibular fistulas which has been accounted for in Table 4. In PICU and NICU 181 procedures totalizing 19\% of all the procedures performed in this period (Table 4).

Regarding the 4 surgeries that are frequently performed at PICU and NICU, the study shows significant statistical difference $(p=0.0001)$, given that venous access was frequently used. 
Table 4. Distribution of the most recurrent surgeries performed at PICU/NICU by an individual specialist in PEDSUR at CHS between 2008 and 2012.

\begin{tabular}{cccc}
\hline Surgeries at PICU/NICU & N & $\%\left(^{*}\right)$ & $\%(\mathbf{n}=\mathbf{9 8 6})$ \\
\hline ECN & 48 & $27 \%$ & $5 \%$ \\
Central Venous Line & 111 & $61 \%$ & $11 \%$ \\
Tracheostomy & 17 & $9 \%$ & $2 \%$ \\
Chest Drainage & 5 & $3 \%$ & $1 \%$ \\
Total & $\mathbf{1 8 1}$ & & $\mathbf{1 8 \%}$ \\
\hline
\end{tabular}

${ }^{*}$ Percentages were calculated based in the total number of children who were operated in PICU/NICU (181). ${ }^{* *}$ In the surgeries in the neonatal period, 13 Colostomies were performed in newborns bearers of High Anorectal Malformation and vestibular fistulae and 2 Gastrostomies in children bearers of Esophageal Atresia without tracheoesophageal fistulae.

\section{Discussion}

The number of children who need specialized surgical procedures is becoming greater with an increase of $21 \%$ since 2005 [1] [11]. The same occurred in the period of the current study in which a $5 \%$ rise was observed $(p<0.0001)$. Despite the increase of SurPed demand, there is a worldwide decline in the number of pediatric surgeons, especially in Brazil where the openings for residents in this specialization didn't surpass $45 \%$ in 2009 [9]. The numbers of children who need specialized surgery are greater than the health system is capable of attending. Consequently, children have been operated by other specialties, such as urology [3]. This is brought about by negligence in essential aspects of child surgery that should be based on clinical evidence and the effective costs of the treatment, aiming at providing benefits to an escalating number of children [12].

The Brazilian Association of Pediatric Surgery (CIPE) determined that high incidence of pediatric diseases; such as phimosis, inguinal and umbilical hernias, gastro-esophagi, cryptorchidism, cervical masses, intestinal atresia, pylorus hypertrophic stenosis, congenital neck torticollis, differential diagnosis of lymphomegaly, hemangiomas, and umbilical malformation is contents of the theoretical program of high incidence of pediatric diseases. According to the present study, the number of surgeries in children increased as well, from 2008 to 2012, but not with significant statistical difference $(p=0.9843)$. HR at CHS are low and high complex attendances, respectively, attend a population of more than 3 million inhabitants, a large group of patients that provides a comprehensive knowledge development in CIPE including Medical Residence Program at CHS (http://www.chshospital.com.br/home/index.htm, 08/10/2016) [10]. Considering high complex procedures, the present study showed a significant statistical difference in central venous access procedure in newborn and small children at the Intensive Care Department (PICU/NICU, $p=0.0001$ ).

Good models of quality professional training, for instance a good surgery and academic residency, attract the young to surgical specialties, as shown by Andriole et al., 2006 [13]. The quality of medical teaching was also a topic of another 
study by Pooja $\mathrm{N}$ et al., 2016. The authors describe that $50 \%$ of students attending medicine courses in England refer to inadequate exposure to quality improvement of Medical Schools in spite of acknowledging its importance in their future careers [7].

Contrary to these authors, de Jesus et al., 2009 published that in the year of 2007 the Health Ministry (HM) offered 168 training openings for Pediatric Surgeons in Brazil. From the openings offered, 162 were divided by three mandatory residency years R1, R2 and R3-a potential graduation of 54 pediatric surgeons per year. However, less than half openings were filled [9]. Only 6 openings are offered for surgeons' upgrading (R4 and R5), essentially in pediatric transplant services (source: CIPE/MS, 2007). The openings are geographically and unproportionally distributed with regards to the territory, given that $67 \%$ are distributed in the Southeast region (32\% in the state of São Paulo and $22 \%$ in Rio de Janeiro). In the North region of the country, there are no available openings for CIPE. Currently, Brazil graduates 23 pediatric surgeons per year [9].

De Jesus et al., 2009, also considered as a criterion of the ideal activity in a surgical center for a pediatric surgeon approximately 3 surgeries/day; four days/ week; 40 weeks/year and each pediatric surgeon has to perform 480 surgeries/ year [9]. Through the data analysis of the current study, it is possible to offer to the PedSur Resident to undertake a task with an individual Specialist of the service, and exposure to an average of 220 surgeries per year of which $36 \%$ are performed in the neonatal period.

The analysis of procedures performed in children from 0 to 12 years old by an individual Pediatric Surgeon of PedSur Service at CHS/SP emphasized the distribution of the most frequent surgeries performed, their degree of complexity, training and qualification. If the statistical data of the 5 Pediatric Surgeons had been computed, certainly the gradual increase of PedSur would be more evident. Despite of PedSur high demand and the prompt increase of training programs in USA [5], there is still a PedSur shortage worldwide, and mainly in Brazil [9] [14]. On the other hand, this study showed an increase of pediatric surgeries in the years of 2008, 2009 and 2012 when comparing with 2010 and 2011, with a significant statistical difference $p<0.0001$.

The data obtained in this retrospective analysis are coincident with literature data with regards to worldwide increase of demand for PedSur. These data suggest a great variety of surgeries in children and the possibility of starting an academic PedSur Medical Residence at HR aimed at training, professional permanence in the region and high quality standard child care [4] [15]. After all, the analyzed data shown herein are solely the result of the work of one of the $6 \mathrm{Pe}$ diatric Surgeons of HR.

\section{References}

[1] Nakayama, D.K., Burd, R.S. and Newman, K.D. (2009) Pediatric Surgery Work- 
force: Supply and Demand. Journal of Pediatric Surgery, 44, 1677-1682. https://doi.org/10.1016/j.jpedsurg.2009.03.036

[2] Lalchandani, P. and Dunn, J.C. (2015) Global Comparison of Pediatric Surgery Workforce and Training. Journal of Pediatric Surgery, 50, 1180-1183.

https://doi.org/10.1016/j.jpedsurg.2014.11.032

[3] Chan, Y.Y., Durbin-Johnson, B. and Kurzrock, E.A. (2016) Pediatric Inguinal and Scrotal Surgery-Practice Patterns in U.S. Academic Centers. Journal of Pediatric Surgery, 51, 1786-1790. https://doi.org/10.1016/j.jpedsurg.2016.07.019

[4] Nakayama, D.K., Burd, R.S. and Newman, K.D. (2009) Clinical and Financial Characteristics of Pediatric Surgery Practices. Journal of Pediatric Surgery, 44, 1304-1308. https://doi.org/10.1016/j.jpedsurg.2009.02.003

[5] Rowe, M.I., Courcoulas, A. and Reblock, K. (1997) An Analysis of the Operative Experience of North American Pediatric Surgical Training Programs and Residents. Journal of Pediatric Surgery, 32, 184-191. https://doi.org/10.1016/S0022-3468(97)90176-7

[6] Fingeret, A.L., Stolar, C.J. and Cowles, R.A. (2013) Trends in Operative Experience of Pediatric Surgical Residents in the United States and Canada. Journal of Pediatric Surgery, 48, 88-94. https://doi.org/10.1016/j.jpedsurg.2012.10.023

[7] Nair, P., Barai, I., Prasad, S. and Gadhvi, K. (2016) Quality Improvement Teaching at Medical School: A Student Perspective. Advances in Medical Education and Practice, 7, 171-172. https://doi.org/10.2147/AMEP.S101395

[8] Teigland, C.L., Blasiak, R.C., Wilson, L.A., Hines, R.E., Meyerhoff, K.L. and Viera, A.J. (2013) Patient Safety and Quality Improvement Education: A Cross-Sectional Study of Medical Students' Preferences and Attitudes. BMC Medical Education, 13, 16. https://doi.org/10.1186/1472-6920-13-16

[9] De Jesus, L.E., Aguiar, A.S., de Campos, M.S.A., Baratella, J.R.S., Ketzer, J.C., Mastroti, R.A. and Amarante, A.C.M. (2009) Formação e demanda do cirurgião pediátrico no Brasil. Revista do Colégio Brasileiro de Cirurgióes, 36, 356-361. https://doi.org/10.1590/S0100-69912009000400016

[10] Lisieux Eyer de Jesus, T.-R., Aguiar, A.S., Amarante, A.C.M., et al. (2016) Portal do Conjunto Hospitalar de Sorocaba, São Paulo, Brasil. http://www.chshospital.com.br/home/index.htm

[11] Malangoni, M.A., Biester, T.W., Jones, A.T., Klingensmith, M.E. and Lewis, F.R. (2013) Operative Experience of Surgery Residents: Trends and Challenges. Journal of Surgical Education, 70, 783-788.

[12] Bickler, S.W. and Rode, H. (2002) Surgical Services for Children in Developing Countries. Bulletin of the World Health Organization, 80, 829-835.

[13] Andriole, D.A., Klingensmith, M.E. and Jeffe, D.B. (2006) Who Are Our Future Surgeons? Characteristics of Medical School Graduates Planning Surgical Careers: Analysis of the 1997 to 2004. Association of American Medical Colleges' Graduation Questionnaire National Database. Journal of the American College of Surgeons, 203, 177-185.

[14] De Jesus, L.E. (2008) Ensinar cirurgia: Como e para quem? Revista do Colégio Brasileiro de Cirurgiões, 35, 136-140. https://doi.org/10.1590/S0100-69912008000200012

[15] Ziegler, M.M. (2004) Pediatric Surgical Training: An Historic Perspective, a Formula for Change. Journal of Pediatric Surgery, 39, 1159-1172. 
Submit or recommend next manuscript to SCIRP and we will provide best service for you:

Accepting pre-submission inquiries through Email, Facebook, LinkedIn, Twitter, etc. A wide selection of journals (inclusive of 9 subjects, more than 200 journals)

Providing 24-hour high-quality service

User-friendly online submission system

Fair and swift peer-review system

Efficient typesetting and proofreading procedure

Display of the result of downloads and visits, as well as the number of cited articles Maximum dissemination of your research work

Submit your manuscript at: http://papersubmission.scirp.org/

Or contact ss@scirp.org 